\title{
Prevalence of Intestinal Parasites among Public and Private School Children below 10 years' at Tarakeswor-10 Manamaiju, Kathmandu, Nepal
}

\author{
Bhumi Gurung, Janak Raj Subedi*, Bijay Chhetri \\ Central Department of Zoology, Tribhuvan University, Kirtipur, Kathmandu, Nepal.
}

Abstract: Introduction: Intestinal parasitosis is one of the chief causes of public health problems particularly in developing countries.

Subject and Methods: Among the various health problems amoebiasis and helminthic infection are still significant among the school pupil in context of Nepal. In this article, we reported the status of intestinal parasitosis among the school pupil in this area. Present study was aimed in finding out the prevalence of intestinal parasitosis in public and private school pupil below 10 years at Tarakeswor-10 (Kathmandu Valley). A total of 160 ( 80 from public and 80 from private school) stool samples collected in clean, dry and screw capped plastic container were studied for the presence of parasites using direct smear method as well as by concentration method.

Results: Overall parasite positive rate was 40\% (64/160). Positive rate was considerably higher in public school children (47.5\%; 38/80) compared with private school $(32.5 \% ; 26 / 80)(\mathrm{P}<0.05)$. No significant difference in positive rate among boys $(53.13 \% ; 34 / 64)$ and girls (46.87\%; 30/64) was observed ( $\mathrm{P}>0.05)$. However, boys in private school had higher positive rate (boys: 57.69\%; girls 42.30\%; P < 0.05). Total six genuses of parasites were identified. Of them, Ascaris lumbricoides was most common followed by Trichuris trichiura, Hookworms, Taenia sp., Entamoeba coli and Enterobius vermicularis.

Conclusion: Parasites positive rate were higher in children who were drinking untreated water. Children had higher positive rate that were from families without toilet.

Keywords: Intestinal parasites, Ascaris lumbricoides, Trichuris trichiura, Hookworms, Taenia sp., Entamoeba coli, Enterobius vermicularis.

\section{INTRODUCTION}

Parasitic infection is more common in developing countries including Nepal [1]. Some parasites don't noticeably affect their host while some others become mature, reproduce or attack organ system which makes their host ill, resulting into a parasitic infection [2]. Although all infectious agents in human are considered as parasites but in convention, parasitic diseases are defined as those caused by protozoa or helminthes [3, 4]. Lack of adequate medical care facilities and social marginalization has increased the susceptibility of the population to other pathogenicities and morbidities associated with parasitic infection [5]. Parasites can live throughout the body but mostly prefer the intestinal wall [6].

Apart from causing morbidity and mortality, intestinal parasites infection have been associated with stunting, physical weakness, low educational performance of school children and also have become the subject of speculation and investigation in dealing to the spreading and severity of other infectious disease like HIV/AIDS and leprosy [7-10].

Intestinal parasite has been predicted to affect some 3.5 billion people worldwide and 450 million are thought to be sick as a

\footnotetext{
* Address correspondence to this author at the Central Department of Zoology, Tribhuvan University, Kirtipur, Kathmandu, Nepal.

E-mail: janzoology@gmail.com
}

result of such infections, the majority is children [11]. In some tropical areas, the prevalence hikes nearly to 100 percent [12]. It is a main socio-economic problem in Nepal, though a hospital based study has shown a falling trend during a decade. Intestinal parasites even in low or moderate number effect on both nutritional and thereby on immune system of individuals leading to numerous morbidity and mortality. The reported prevalence of intestinal parasitosis in Nepal differs considerably with over 90 percent prevalence in some areas. Overall helminthic infections only rank fourth in the top ten lists of diseases in Nepal. The intestinal parasitosis remains to be one of the chief problems in bigger towns like Kathmandu as well because of the pollution of the drinking water and soil by feces [13]. Almost, $10 \%$ of the world's populations are infected by only with Entamoeba histolytica and each year 65,000, 60,000 and 70,000 deaths are related with Ascaris lumbricoides, hookworm and Trichuris trichiura, respectively [11]. More than half population of the world reportedly lives in despair and pain, and suffers vast financial loss attributed to parasitosis alone [14]. The intestinal parasitosis seems to be one of the major health problem among pupil in study area as well. So, the main aim of this research work was to investigate whether the intestinal parasites are more prevalent among public school children than private school children below 10 years' in Tarakeshwor-10 municipality. 


\section{MATERIAL \& METHODS}

\section{Study Area}

The study area, Tarakeshwar lies in Kathmandu district and has an area of total $34.9 \mathrm{~km} 2$ with over-crowded residence of 81,443 populations [15]. Ethnicities such as Newer, Brahmin, Chhetri, Tamang, Magar are those groups mainly residing in this area. From socioeconomic point of view, the people of this area include all- low, medium and high level where most of them are engaged in labor and business kind of occupation. As the area is within capital city of the country, it is facilitated by all kind of services (Fig. 1).

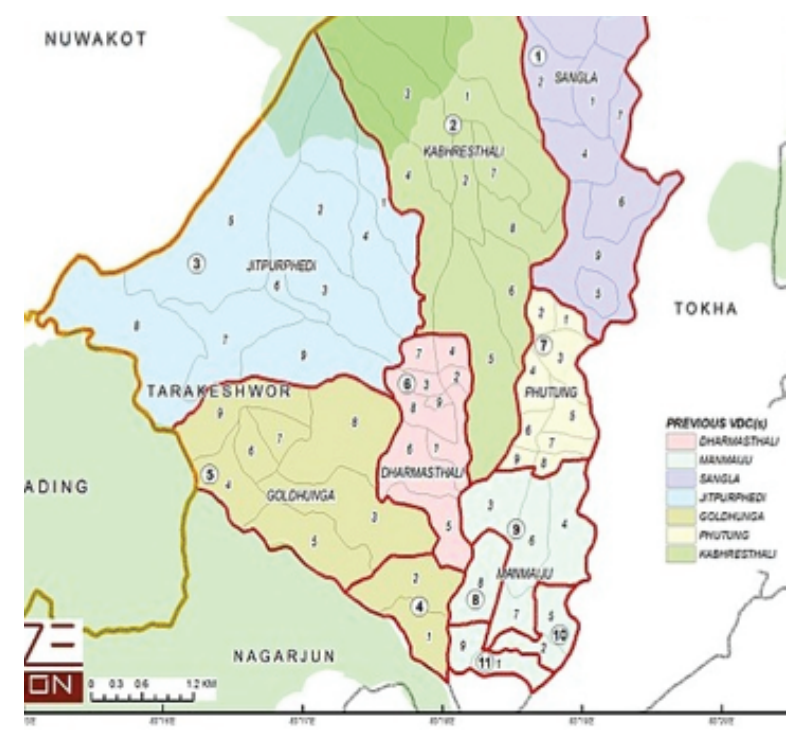

Fig. (1). Tarakeshwor Municipality.

\section{METHODS}

\section{Stool Collection and Processing}

Systematic Random Sampling technique was applied in selection of pupil for the sample and data collection from the public school of selected area. Collection of samples was carried out at the first hour (10 to 11 A.M) of a day when schools were in session. The pupils were taught in brief about the importance of the examination of stool to detect the parasite and how to collect stool samples with the aid of their teachers and parents. After properly instructing children about stool sample collection method, they were provided labeled collection vials and application sticks. Each student was told to collect about $2 \mathrm{gm}$. of fresh stool. Every specimen was checked for its labeling and quantity. The portion of stool samples were preserved in $2.5 \%$ potassium-dichromate solution and brought to the laboratory at Central Department of Zoology, TU, Kirtipur, Kathmandu then immediately processed to find cysts, trophozoites, eggs and larva of intestinal parasites by direct smear method [16] and concentration method [17].
Direct smear examination was done for the detection and identification of helminths eggs or larva and protozoal cysts, oocytes, trophozoites by wet preparation i.e unstained smear preparation and stained smear preparation [16]. For unstained smear preparation of sample a drop of normal saline was taken in a clean glass 1-2 drops of stool sample was mixed over it making its consistency thin and clear then observed under microscope [16]. For stained smear preparation of sample, a drop of 5 times diluted Logol's iodine solution was taken on a glass slide and mixed 1-2 drops of stool sample with it. The preparation was then observed under microscope [16]. Beside the direct stool smear preparation and examination method, for some doubtful samples, indirect method of examination was also applied.

The fecal samples were coprological examined by concentration technique (Floatation and Sedimentation). A beaker was used where nearly 3 gram of fecal sample was placed with $42 \mathrm{ml}$ of water and then filtered. The filtrate solution was centrifuged for around 5 minutes. $\mathrm{NaCl}$ was used to saturate the filtrate and again filtrate was centrifuged. The mixture from top was examined by adding methylene blue and the sediment was stained with iodine solution to detect eggs, trophozoites and cysts of parasites $[17,18]$.

Further, scotch cellulose adhesive tape procedure was followed, as the egg of E. vermicularis was found in stool sample of one children therefore, to confirm whether the children was suffered from the infection of this parasite or not. As usually, E. vermicularis infection is diagnosed by demonstrating the presence of eggs on the perianal and perineal skin. Approximately $10 \mathrm{~cm}$ long clean cellophane tape was held between thumbs and forefinger with sticky surface outward and sticky side was pressed against skin across the anal opening with even, thorough pressure. Then, the sticky side was gently taken out and placed on the surface of clear glass slide for examination [17].

\section{Calibration of Eggs, Cysts and Larva}

Ocular and stage micrometer were used for calibration of length, breadth and diameter of parasites eggs, cysts and larva. They were measured with the calibration factors.

Calibration Factor (C.F.) for 10x=10.37micrometer

Calibration Factor (C.F.) for 40x=2.588micrometer

\section{Identification of the Eggs, Cysts and Larva}

The identification and confirmation of the eggs, cysts and larva were made by comparing the structure, color, size of eggs, cysts and larva from published books, literature and journals [11].

\section{Statistical Analysis}

The collected data from the field survey and laboratory reports were statistically analyzed with the help of Microsoft 
Excel 2007 and Pearson's Chi-squared test performed by R 3.4.1 version software package [19]. $\mathrm{P}<0.05$ was considered for the statistically significance difference.

\section{RESULTS}

The total 160 subjects were selected and stool samples were collected from different classes (Nursery to grade-two) of the school and examined from August to September, 2017.

Table 1. General Prevalence of Intestinal Parasites.

\begin{tabular}{|c|c|c|c|c|}
\hline Type of School & $\begin{array}{c}\text { +ve cases } \\
\mathbf{n}(\mathbf{\%})\end{array}$ & $\begin{array}{c}\text {-ve cases } \\
\mathbf{n}(\mathbf{\%})\end{array}$ & $\mathbf{X}^{\mathbf{2}}$ & $\boldsymbol{P}$ \\
\hline Public & $38(47.5)$ & $42(52.5)$ & \multirow{2}{*}{20} & \multirow{2}{*}{0.00017} \\
\cline { 1 - 3 } Private & $26(32.5)$ & $54(67.5)$ & & \\
\hline
\end{tabular}

Positive rate was considerably higher in public school children $(47.5 \% ; 38 / 80)$ compared with private school $(32.5 \%$; 26/80) $(\mathrm{P}<0.05)$ (Table 1).

Table 2. Gender wise Prevalence of Intestinal Parasites.

\begin{tabular}{|c|c|c|c|c|}
\hline Gender & $\begin{array}{c}\text { +ve cases } \\
\text { n (\%) }\end{array}$ & $\begin{array}{c}\text {-ve cases } \\
\text { n (\%) }\end{array}$ & $\mathbf{X}^{\mathbf{2}}$ & $\boldsymbol{P}$ \\
\hline Boys & $34(53.13)$ & $30(46.87)$ & \multirow{2}{*}{1} & \multirow{2}{*}{0.801} \\
\hline Girls & $30(46.87)$ & $34(53.13)$ & & \\
\hline
\end{tabular}

No significant difference in positive rate among boys $(53.13 \% ; 34 / 64)$ and girls $(46.87 \% ; 30 / 64)$ was observed $(\mathrm{P}>$ 0.05 ) (Table 2).

\section{Distribution of Protozoan and Helminthic Infection}

Of total 64 positive samples, the distribution of helminthic infection $69(95.83 \%)$ were higher than the protozoan infection 3 (4.17\%). Even, among the children of particular private and public schools the helminthic infection was more prevalent than protozoan (Fig. 2).

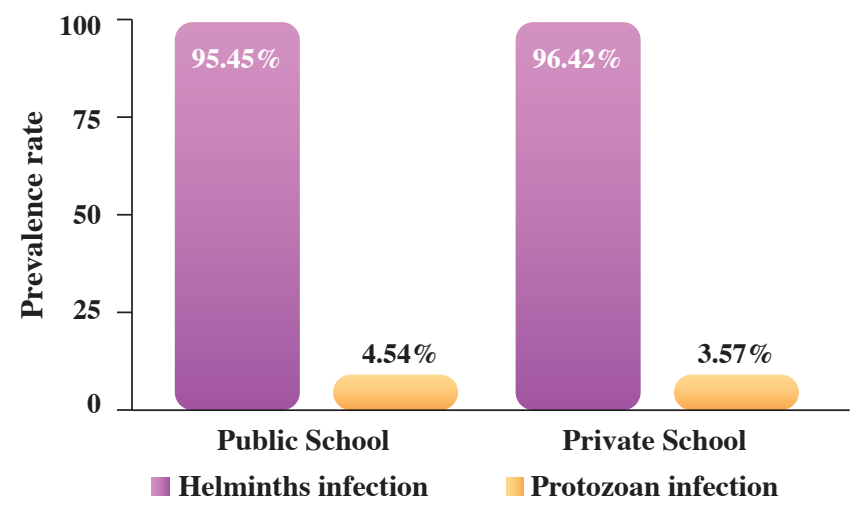

Fig. (2). Distribution of Protozoan and Helminthic Infection in Public and Private School.

\section{Prevalence of Individual Intestinal Parasites}

Total six intestinal parasites were recorded among them, $A$. lumbricoides was higher prevalent in children of both schools followed by T. trichura, Hookworm, Taenia sp., E. coli and E. vermicularis. The pupil of public school has got maximum distribution of parasites in comparison to private school (Table 3).

Table 3. Prevalence of Specific Intestinal Parasites.

\begin{tabular}{|l|l|c|c|c|c|}
\hline \multirow{2}{*}{ S.N. } & \multirow{2}{*}{ Parasites } & \multicolumn{5}{|c|}{ Type of School } \\
\cline { 3 - 6 } & & \multicolumn{2}{|c|}{ Public } & \multicolumn{2}{|c|}{ Private } \\
\cline { 3 - 6 } & No. & Infected \% & No. & Infected \% \\
\hline \multicolumn{7}{|c|}{ Helminthes } \\
\hline 1. & A. lumbricoides & 29 & 76.32 & 22 & 84.62 \\
\hline 2. & T. trichura & 5 & 13.16 & 3 & 11.54 \\
\hline 3. & Hookworm & 4 & 10.53 & 1 & 3.85 \\
\hline 4. & E. vermicularis & 1 & 2.63 & - & - \\
\hline 5. & Taenia sp. & 3 & 7.89 & 1 & 3.85 \\
\hline \multicolumn{7}{|c|}{ Protozoan } \\
\hline 6. & Entamoeba coli & 2 & 5.26 & 1 & 3.85 \\
\hline
\end{tabular}

\section{Intensity of Single Infection}

Altogether $84.21 \%$ (32/38) stool samples were found single parasitic infected where the parasite $A$. lumbricoides was observed higher prevalent $81.25 \%$ (Table 4).

Table 4. Intensity of Single Infection.

\begin{tabular}{|l|l|c|c|c|c|}
\hline \multicolumn{6}{|c|}{ Public School } \\
\hline S.N. & \multicolumn{1}{|c|}{ Parasites } & No. & $\begin{array}{c}\text { \% of } \\
\text { ve cases }\end{array}$ & $\begin{array}{c}\text { No. of } \\
\text { infected } \\
\text { male }\end{array}$ & $\begin{array}{c}\text { No. of } \\
\text { infected } \\
\text { female }\end{array}$ \\
\hline 1. & A. lumbricoides & 26 & 81.25 & 12 & 14 \\
\hline 2. & T. trichura & 2 & 6.25 & 1 & 1 \\
\hline 3. & Taenia sp. & 3 & 9.38 & 2 & 1 \\
\hline 4. & Hookworm & 1 & 3.13 & 1 & - \\
\hline & Total & 32 & 100 & 16 & 16 \\
\hline \multicolumn{7}{|c|}{ Private School } \\
\hline S.N. & \multicolumn{1}{|c|}{ Parasites } & No. & $\begin{array}{c}\text { \% of } \\
+\mathbf{v e ~ c a s e s ~}\end{array}$ & $\begin{array}{c}\text { No. of } \\
\text { infected } \\
\text { male }\end{array}$ & $\begin{array}{c}\text { No. of } \\
\text { infected } \\
\text { female }\end{array}$ \\
\hline 1. & A. lumbricoides & 21 & 87.5 & 11 & 10 \\
\hline 2. & T. trichura & 2 & 8.33 & 1 & 1 \\
\hline 3. & Taenia sp. & 1 & 4.17 & 1 & - \\
\hline 4. & Hookworm & - & - & - & - \\
\hline & Total & 24 & 100 & 13 & 11 \\
\hline
\end{tabular}




\section{Intensity of Double Infection}

Double parasitic infection was reported as $15.79 \%(6 / 38)$ in total positive samples where equal rate of prevalence of double parasites were observed (Table 5).

Table 5. Intensity of Double Infection.

\begin{tabular}{|c|c|c|c|}
\hline \multicolumn{4}{|c|}{ Public School } \\
\hline S.N. & Parasites & No. & $\begin{array}{c}\% \text { of }+v e \\
\operatorname{cases}(n=6)\end{array}$ \\
\hline 1. & A. lumbricoides + Hookworm & 1 & 16.67 \\
\hline 2. & T. trichura + E. coli & 1 & 16.67 \\
\hline 3. & T. trichura + Hookworm & 1 & 16.67 \\
\hline 4. & E. vermicularis + A. lumbricoides & 1 & 16.67 \\
\hline 5. & Hookworm + E. coli & 1 & 16.67 \\
\hline 6. & A. lumbricoides + T. trichura & 1 & 16.67 \\
\hline \multicolumn{4}{|c|}{ Private School } \\
\hline S.N. & Parasites & No. & $\begin{array}{c}\% \text { of }+ \text { ve } \\
\text { cases }(n=6)\end{array}$ \\
\hline 1. & A. lumbricoides + Hookworm & 1 & 50 \\
\hline 2. & T. trichura + E. coli & 1 & 50 \\
\hline 3. & T. trichura + Hookworm & - & - \\
\hline 4. & E. vermicularis + A. lumbricoides & - & - \\
\hline 5. & Hookworm + E. coli & - & - \\
\hline 6. & A. lumbricoides + T. trichura & - & - \\
\hline
\end{tabular}

\section{DISCUSSION}

Among the identified parasites in the stool samples, gastrointestinal parasites in public school such as helminthes (A. lumbricoides, T. trichura, Hookworm, E. vermicularis and Taenia sp.) and protozoan (Entamoeba coli) were dominant, probably due to poor hygienic environment, lack of education, drinking untreated water and poor socio-economic condition of family. This assumption can be supported by the occurrence of gastrointestinal parasites among the public and private school pupil in rural area of southern Nepal [20], in suburban public school pupil in Kathmandu, Nepal [21], in northeastern part of Kathmandu valley [22] and in a rural area of Kathmandu Valley [23]. Therefore, it seems to be attributed to poor sanitary environment, lack of education, drinking contaminated water and low socio-economic status of the family [24].

The present study showed no significant difference in prevalence of gastrointestinal parasitic infection among boys and girls of school children. This finding resembles with the parasitic infection in school children in Thimi area Kathmandu valley [25]. Similar result was also shown by many studies in Nepal [13, 26-29], elsewhere by [30]. This make sense that school children, both boys and girls are susceptible to parasitic infection as the infection in children is determined by family income, quality of sewage disposal, nutritional status and behavioral characteristics [31-33].

The present study observed $40 \%$ prevalence rate of intestinal parasites which was lower than prevalence rate reported by [26] and higher than the studies reported by [27] and [34]. Prevalence of infections was higher for helminthes $(83.33 \%)$ compared to protozoa (16.66\%). A. lumbricoides noted as the higher rank (76.32\%) among all listed parasites. Same result was also showed by the previous studies [13, 35-38]. This might be due to over dispersion of Ascaris egg in the environment as about 200000-250000 eggs are laid by single female worm and as well poor hygiene habits supporting in its chances [34]. Whereas, the infection of protozoan in this study was observed as low prevalent with recorded only one species- E.coli. Study by $[22,39,40]$ had also reported E. coli as the most common protozoan parasite. This might be due to using contaminated water, as the possibility of contamination of drinking water was due to close running of water pipe and sewage line in Kathmandu [40].

The present finding was maximum for single parasitic infection (84.21\%) and (15.79\%) were detected as double parasitic infection from examined subjects. The given result was in agreement with the studies in Nepal and elsewhere in world [34, 41-44]. In contrast, some studies had reported higher prevalence of multiple infections [22, 45]. In this study, Ascaris+Hookworm (25\%) and Trichura+E.coli $(25 \%)$ were noted as prevalent double parasitic infection overall, the study done by [44] had reported higher rate of infection due to Ascaris+Hookworm than the rate of this study followed by Ascaris+trichuris infection.

\section{CONCLUSION}

Almost 47.5\% subjects were recorded as positive cases where helminthes parasitic infection were prevalent than protozoan parasitic infection. Altogether 6 species of parasites were encountered with most common helminthes parasite $A$. lumbricoides. This shows that intestinal parasitic infection is still prevalent as major health problem among school children. Although the study area lies in Kathmandu valley, transmission of infections were generally due to poor sanitary habits, use of contaminated water, improper disposal management and somewhat lack of knowledge related infections. Awareness on disease infection, improvement in hygiene and conduction of supportive programs for parents to raise socio-economic conditions may reduce parasites in this area.

\section{CONFLICT OF INTEREST}

Declared none. 


\section{ACKNOWLEDGEMENTS}

We acknowledge gratitude to Assoc. Prof. Dr. Mahendra Maharjan for his assistance in the research work. Thanks to Heads of Central Departments of Zoology and Environmental Science for providing necessary facilities in lab. We are also grateful to all the teaching and non-teaching staffs of "Central Department of Zoology".

\section{REFERENCES}

[1] Baral R, Jha P, Amatya R, Khanal B. Prevalence of intestinal parasitic infections among patients attending in a tertiary care hospital of eastern region of Nepal - A retrospective, laboratory based study. Asian J Med Sci 2017; 8(3): 55-9.

DOI: 10.3126/ajms.v8i3.16909

[2] Kinman T. Parasitic infections. 2013; Available at: http://www.healthline.com/health/parasitic-infections. [Accessed on 1 March 2018].

[3] Matthys B, Bobieva M, Karimova G, Mengliboeva Z, Jean-Richard V, Hoimnazarova M. Prevalence and risk factors of helminthes and intestinal protozoan infection among children from primary school in western Tajikistan. Parasite Vectors 2011; 4(1): 195. DOI: 10.1186/1756-3305-4-195

[4] Alyousefi NA, Mahdy MA, Mahmud R, Lim YA. Factors associated with high prevalence of intestinal protozoan infections among patients in Sana'a city, Yemen. PLoS One 2011; 6(7): e22044. DOI: 10.1371/journal.pone.0022044

[5] Keiser J, Utzinger J. Efficacy of current drugs against soil-transmitted helminth infections: Systematic review and meta-analysis. J Am Med Assoc 2008; 299(16): 1937-48. DOI: $10.1001 /$ jama.299.16.1937

[6] WHO. Training manual on diagnosis of intestinal parasites. Geneva, Switzerland: World Health Organization 2004.

[7] Nokes C, Grantham-McGregor SM, Sawyer AW, Cooper ES, Robinson BA, Bundy DA. Moderate to heavy infections of Trichuris trichiura affect cognitive function in Jamaican schoolchildren. Parasitology 1992; 104: 539-47.

DOI: $10.1017 / \mathrm{S} 0031182000063800$

[8] Nokes C, Bundy DA. Does helminth infection affect mental processing and educational achievement? Parasitol Today 1994; 10(1): 14-8. DOI: 10.1016/0169-4758(94)90348-4

[9] Bentwich Z, Klinkovich A, Weisman Z. Immune activation is a dominant factor in the pathogenesis of African AIDS. Immunol Today 1995; 16: 187-91.

DOI: $10.1016 / 0167-5699(95) 80119-7$

[10] Diniz LM, Zandonade E, Dietze R, Pereira FE, Ribeiro-Rodrigues R. Short report: Do intestinal nematodes increase the risk for multibacillary leprosy? Am J Trop Med Hyg 2001; 65(6): 852-4. DOI: 10.4269/ajtmh.2001.65.852

[11] World Health Report. Conquering suffering enriching.
Geneva, Switzerland: World Health Organization 2000.

[12] Uga S, Rai SK, Kimura K, et al. Parasites detected from diarrheal stool samples collected in Kathmandu, Nepal. Southeast Asian J Trop Med Public Health 2004; 35: 19-23.

[13] Rai DR, Rai SK, Sharma BK, Ghimire P, Bhatta DR. Factors associated with intestinal parasitic infection among school children in a rural area of Kathmandu valley, Nepal. Nepal Med Coll J 2005; 7(1): 43-6.

[14] Rai SK, Gurung CK. Intestinal parasitic infections in high schoolchildren of Birgunj city. J Inst Med (Nepal) 1986; 8: 33-8.

[15] Central Bureau of Statistics. National Population and Housing Census 2011. Kathmandu, Nepal: Village Development Committee/Municipality 2011; Available at: https://unstats.un.org/unsd/demographic-social/census/documents/Nepal/Nepal-Census-2011-Vol1.pdf. [Accessed on 1 December 2018].

[16] Chatterji KD. Parasitology (Protozoology and Helminthology) in Relation to Clinical Medicine. $11^{\text {th }}$ ed. India: Medical Publishers 2001; p. 236.

[17] Arora DR, Arora BB. Medical parasitology. In: Jain SK, Jain VK, Eds. Relative Sizes of Morphological Forms of Various Protozoa and Helminth Eggs. New Delhi, India: CBS Publishers and Distributers Private Limited 2015; pp. 274-5.

[18] Zajac AM, Conboy GA, Eds. Veterinary Clinical Parasitology. $8^{\text {th }}$ ed. Oxford, UK: Blackwell Publishing 2012.

[19] R Core Team. R: A language and environment for statistical computing. R Foundation for Statistical Computing, Vienna, Austria. 2018; Available online at https:/www.R-project.org/

[20] Sherchand JB, Ohara H, Sherchand S, Cross JH, Shrestha MP. Intestinal parasitic infections in rural areas of Southern Nepal. J Inst Med (Nepal) 1997; 19: 115-21.

[21] Ishiyama S, Rai SK, Ono K, et al. Study of enteropathogens and its predisposing factors in suburban public school children in Kathmandu, Nepal. Nepal Med Coll J 2001; 3: 5-9.

[22] Sharma BK, Rai SK, Rai DR, Chaudhary DR. Prevalence of intestinal parasitic infestation in school children in the northeastern part of Kathmandu valley, Nepal. Southeast Asian J Trop Med Public Health 2004; 35(3): 501-5.

[23] Rai SK, Nakanishi M, Upadhyay MP, et al.. Effect of intestinal helminth infection on some nutritional parameters among rural villagers in Nepal. Kobe J Med Sci (Japan) 1998; 44: 91-8.

[24] Khanal R, Upadhaya S, Lamichhane P. Enteric parasitic infections among school children at Rupandehi, Nepal. J Uni Coll Med Sci 2006; 4(2): 30-3.

DOI: $10.3126 /$ jucms.v4i2.19089 
[25] Shrestha SK, Rai SK, Vitrakoti R, Pokharel P. Parasitic infection in school children in Thimi area, Kathmandu valley. J Nepal Assoc Med Lab Sci 2009; 10(1): 31-3.

[26] Khadka KS, Kaphle HP, Gurung K, Shah Y, Sigdel M. Study of intestinal parasitosis among school going children in Pokhara, Nepal. J Health Allies Sci 2013; 3(1): 47-50.

[27] Pradhan P, Bhandary S, Shakya PR, Acharya T, Shrestha A. Prevalence of Intestinal parasitic infection among public school children in a rural village of Kathmandu valley. J Nepal Med Coll 2014; 16(1): 50-3.

[28] Gyawali N, Amatya R, Nepal HR. Intestinal Parasitosis in school going children of Dharan Municipality. Nepal Trop Gastroenterol 2009; 30(3): 145-7.

[29] Shrestha B. Intestinal parasitic infestation in healthy school children of Lalitpur district. J Nepal Med Assoc 2001; 41: 266-70. DOI: $10.31729 /$ jnma.743

[30] Champetier de Ribes G, Fline M, Desormeaux AM, et al. Intestinal helminthiasis in school children in Haiti in 2002. Bull Soc Pathol Exot 2002; 98(2): 127-32.

[31] Iiechukwu GC, Iiechukwu CG, Ozumba AN, Ojinnaka NC, Ibe BC, Onwasigwe CN. Some behavioural risk factors for intestinal helminthiasis in nursey and primary school children in Enuga, South eastern Nigeria. Nigerian J Clin Pract 2010; 13(3): 288-93.

[32] Barra M, Bustos L, Ossa X. Inequality in the prevalence of intestinal parasitic infections among school children from urban and rural schools. Rev Med Chile 2016; 144: 886-93. DOI: $10.4067 / \mathrm{S} 0034-98872016000700009$

[33] Quihui L, Valencia M, Crompton D, et al. Prevalence and intensity of intestinal parasitic infection in relation to nutritional status in Mexican school children. Trans R Soc Trop Med Hygiene 2004; 98: 653-9.

DOI: $10.1016 /$ j.trstmh.2003.12.017

[34] Shrestha A, Rai SK, Basnyat SR, Rai CK, Shakya B. Soil transmitted helminthiasis in Kathmandu, Nepal. Nepal Med Coll J 2007; 9(3): 166-9.

[35] Khanal LK, Chaudhary DR, Rai SK, Sapkota J, Barakoti A, Amatya R. Prevalence of intestinal worm infestation among school children in Kathmandu, Nepal. Nepal Med Coll J 2011; 13(4): 272-4.
[36] Abossies A, Seid M. Assessment of the prevalence of intestinal parasitosis and associated risk factors among primary schoolchildren in Chencha town, Southern Ethiopia. Biomed Central Public Health 2014; 14: 166.

DOI: $10.1186 / 1471-2458-14-166$

[37] Korzeniewski K, Augustynowicz A, Smolen A, Lass A. Epidemiology of intestinal parasitic infections in school children in Ghazni Province, Eastern Afghanistan. Pakistan J Med Sci 2015; 31(6): 1421-5. DOI: 10.12669/pjms.316.8889

[38] Mukhiya RK, Rai SK, Karki AB, Prajapati A. Intestinal Protozoan Parasitic Infection among School Children of Sindhuli, Nepal. J Nepal Health Res Council 2012; 10(22): 204-7.

[39] Rai SK, Hirai K, Abe A, et al. Study on enteric parasitosis and nutritional status of school children in remote hilly areas in Nepal. Nepal Med Coll J 2004; 6(1): 1-6.

[40] Easow JM, Mukhopadhyay C, Wilson G, Gha S, Jalan BY, Shivananda PG. Emerging opportunistics protozoan and intestinal pathogenic protozoal infestation profile in children of western Nepal. Nepal Med Coll J 2005; 7: 134-7.

[41] Kunwar R, Acharya L, Karki S. Decreasing prevalence of intestinal parasitic infection among school-aged children in Nepal: a systematic review and meta-analysis. Trans R Soc Trop Med Hyg 2016; 110(6): 324-32.

DOI: $10.1093 /$ trstmh/trw033

[42] Hailegebriel T. Prevalence of intestinal parasitic infections and associated risk factors among students at Dona Berber Primary School, Bahir Dar, Ethiopia. BioMed Central Infect Dis 2017; 17(1): 362. DOI: 10.1186/s12879-017-2466-X

[43] Abera A, Nibret E. Prevalence of gastro-intestinal helminthic infections and associated risk factors among schoolchildren in Tilili town, northwest Ethiopia. Asian Pacific J Trop Med 2014; 7(7): 525-30. DOI: 10.1016/S1995-7645(14)60088-2

[44] Shakya B, Shrestha S, Madhikarmi NL, Adhikari R. Intestinal parasitic infection among school children. J Nepal Health Res Council 2012; 10(1): 20-3.

[45] Dada-Adegbola HO, Oluwatoba AO, Falade CO. Prevalence of multiple intestinal helminthes among children in a rural community. Afr J Med Sci 2005; 34(3): 263-7. 